\title{
Perspectives
}

\section{Structure and Function of the T Cell Antigen Receptor}

\author{
Arthur Weiss \\ Howard Hughes Medical Institute, Division of Rheumatology and Clinical Immunology, Departments of Medicine and of Microbiology \\ and Immunology, University of California, San Francisco, San Francisco, California 94143
}

\begin{abstract}
Introduction
The mechanisms by which $\mathrm{T}$ lymphocytes recognize and respond to antigen are of great importance in understanding human disease and in the development of therapeutic interventions for immune-mediated diseases. The $T$ cell response to microorganisms is fundamentally important for survival of the host. The importance of this response is exemplified by the impact of the current epidemic of the acquired immune deficiency syndrome in which a subset of $\mathrm{T}$ cells is the target of the human immunodeficiency virus. The $T$ cell response to polymorphic determinants of the major histocompatibility complex (MHC) ${ }^{1}$ molecules represents the major barrier to the successful transplantation of solid organs and bone marrow. Inappropriate responses by $\mathrm{T}$ cells to self-components can lead to autoimmune disease.

During the past few years considerable progress has been made in our understanding of the molecular events involved in $T$ cell recognition and in the processes involved in initiating the $T$ cell response to foreign antigens. A large number of cell surface molecules on the $T$ cell have been implicated in the recognition events that result in the initiation of a $T$ cell response. However, of primary importance is the $T$ cell antigen receptor (TCR) because it must be involved in the regulation of all antigen-specific $T$ cell responses.
\end{abstract}

\section{$T$ cell antigen receptor recognition: the unique nature of the ligand}

Unlike B lymphocytes which utilize membrane immunoglobulin to recognize antigenic determinants of native proteins, $T$ cells use a structurally distinct clonally distributed receptor to recognize a different form of antigen on the surface of an antigen presenting cell (APC) such as a macrophage, epithelial cell, or B cell. $\mathrm{T}$ cells simultaneously recognize antigen as well as polymorphic determinants on a self-MHC molecule, a phenomenon termed "MHC restriction." Understanding MHC restriction requires explanation of the nature of the antigen as well the $T$ cell receptor that not only recognizes antigen but also self-MHC molecules.

The molecular characterization of the antigen perceived by

Received for publication 16 May 1990 and in revised form 3 July 1990.

1. Abbreviations used in this paper: APC, antigen presenting cell; MHC, major histocompatibility complex; TCR, T cell antigen receptor.

J. Clin. Invest.

(C) The American Society for Clinical Investigation, Inc.

0021-9738/90/10/1015/08 $\$ 2.00$

Volume 86, October 1990, 1015-1022 the $T$ cell revealed that, in contrast to B cells, $T$ cells do not recognize native protein antigens. APC's process exogenous antigens through an acidic choroquin-sensitive endosomal compartment (reviewed in reference 1). Proteolytically treated antigens or short peptides can substitute for native antigen in stimulating $T$ cells. This is consistent with the current view that $T$ cells recognize short peptides derived from more complex protein antigens as a result of proteolytic processing.

It is the source of the peptide that determines whether it is presented in association with class I (HLA-A, B, C) or class II (HLA-DR, DP, DQ) MHC molecules. Peptides derived from proteins synthesized endogenously within the APC, including proteins derived from viruses which have infected the cell, are presented in association with class I MHC molecules (2). A similar situation may apply for alloantigens (3). In contrast, peptides derived from exogenous sources or from antigens which are taken up through endocytic pathways, and proteolytically processed, are presented in association with class II MHC molecules (4).

The precise mechanisms by which MHC molecules associate with peptide antigens are not known. With a few exceptions involving class I MHC molecules (5), direct peptide binding has been demonstrated primarily with purified class II MHC molecules and peptides (6). These peptides can associate with class II MHC molecules on the surface of the APC, an event which occurs most often experimentally in vitro, but in vivo is more often thought to occur when peptides generated within a compartment linked to the endocytic pathway interact with class II MHC molecules (4). Peptides derived from endogenously synthesized molecules appear to bind to immature forms of the heavy chain of class I molecules in a preGolgi compartment (7). The mechanism responsible for degradation of endogenously synthesized proteins to peptides is not known (discussed in reference 2). Variability in the ability of distinct peptides to bind to polymorphic class II MHC molecules has been well documented (8). A similar degree of specificity exists for the interaction of peptides with class I MHC molecules. The specificity of this interaction helps to explain some of the previous observations on immune response genes.

The interaction between the peptide and the MHC molecule has been most clearly delineated from the crystal structure of class I MHC molecules (9). The structure, as might be perceived by the TCR, consists of two $\alpha$ helices, which contain many of the class I MHC polymorphic residues, lying on a floor of eight antiparallel $\beta$ sheets. Together, the $\alpha$ helices and $\beta$ sheets form a groove in which peptide antigen lies. A similar structural motif is thought to hold for class II MHC molecules. A model has been proposed in which distinct regions of the TCR interact separately with peptide antigen or with portions of the surrounding MHC molecule (10). 
Structure of the T cell antigen receptor and its function in antigen recognition

The TCR is a seven-chain molecular complex with both variable and invariant components (Fig. 1) (11). It consists of an antigen/MHC (ligand) binding subunit, a disulfide-linked heterodimer $(\mathrm{Ti})$, that is noncovalently associated with a fivechain complex $\left(\mathrm{CD} 3 \delta, \epsilon, \gamma\right.$, and $\left.\zeta_{2}\right)$ that is thought to play a role in signal transduction (see below). The association of $\mathrm{Ti}$ with CD3 is intimate and obligatory. Chemical cross-linking of Ti $\beta$ and CD3 $\gamma$ chains on unstimulated T cells has been accomplished (12). Absence of the Ti or $\zeta$ chains in mutant cell lines prevents cell surface expression of the remaining chains of the TCR complex $(13,14)$. The defective assembly of the TCR has been associated with a selective $T$ cell immunodeficiency (15).

The structural domains of $\mathrm{Ti}$ and $\mathrm{CD} 3$ responsible for their physical and functional association is of considerable interest. A feature of Ti and CD3 that may be important in their association is the unusual presence of oppositely charged amino acids within the transmembrane domains of all $\mathrm{Ti}$ and CD3 chains (11). Mutational analysis has provided evidence that the specific conserved basic residues of $\mathrm{Ti}$ are required for structural assembly of the complex (16). More recent studies with chimeric molecules demonstrate that the structural and functional basis of the association between $\mathrm{Ti}$ and $\mathrm{CD} 3$ chains is contained within regions of the $\mathrm{Ti}$ chains containing these transmembrane domains (Tan, L., J. Turner, and A. Weiss, submitted for publication). These domains also appear to be responsible for targeting unassembled chains of the complex to a degradative pathway linked to the endoplasmic reticulum (17).

On most human $\mathrm{T}$ cells which express CD4 or CD8, Ti consists of a disulfide-linked 40-44 kD $\beta$ chain and a more acidic $\alpha$ chain of 47-54 kD. Each of these chains has constant and variable domains and each is derived from immunoglobulinlike genes (see below). The $\alpha$ and $\beta$ chains contain all of the information necessary for antigen and MHC specificity. cDNAs or rearranged genomic DNA encoding the $\alpha$ and $\beta$ chains, derived from cells with well-characterized antigen and MHC specificities, can transfer both antigen and MHC reactivity to cell lines or to $\mathrm{T}$ cells of transgenic mice, respectively $(18,19)$.

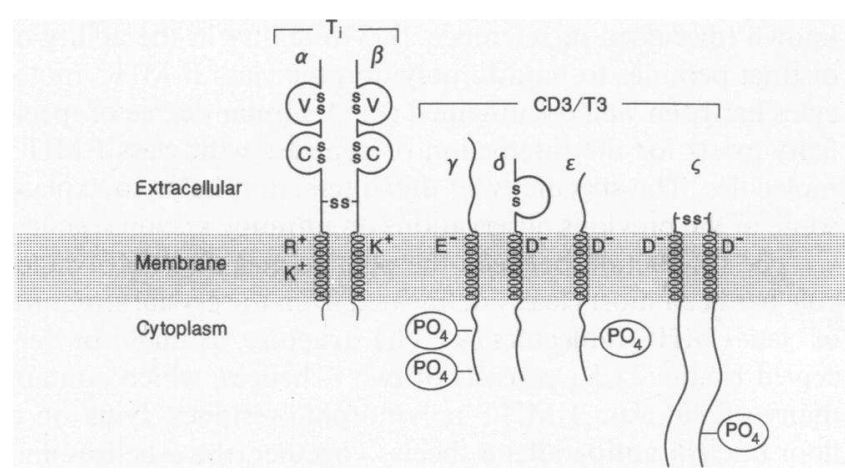

Figure 1. Schematic representation of the structure of the $\mathrm{T}$ cell antigen receptor. The single-letter abbreviations for basic and acidic amino acids contained within the membrane is shown. Phosphorylation sites on the $\zeta, \gamma$, and $\delta$ chains are not meant to depict stoichiometry or positions of these modifications.
The reactivity of $\mathrm{T}$ cells for antigenic peptides associated with class I or II MHC molecules is dependent on the selection of cells expressing TCRs with specificity for class I or class II MHC during thymic ontogeny through a process termed thymic education. Immature thymocytes which coexpress CD4 and CD8 cell surface molecules and express low levels of Ti $\alpha \beta$ are "positively selected" and allowed to continue their developmental maturation (20). This maturational process ultimately results in CD8 or CD4 single positive cells that express high levels of $\alpha / \beta$ TCR which recognize class I or II MHC molecules, respectively. However, during the maturational process, elimination of T cells which express $\alpha / \beta$ TCR that react too strongly with self antigens occurs through an active suicide process $(21,22)$. Aberrancies in these mechanisms may permit the emergence of autoreactive $\mathrm{T}$ cells. Cyclosporin A can prevent clonal deletion in the thymus resulting in the emergence of $\mathrm{T}$ cells which would otherwise be deleted (23). This may explain why some transplant patients or animals treated with cyclosporin manifest autoimmune phenomena $(24,25)$.

Peripheral $\mathrm{T}$ cells are commonly divided into subpopulations based on their expression of CD4 and CD8. The strong bias of CD4+ and CD8 $+\mathrm{T}$ cells expressing $\alpha / \beta$ TCR for extracellular and intracellular infectious organisms, respectively, is determined during thymic selection and is also better understood in the context of the interaction of the CD4 and CD 8 molecules with MHC molecules and the functions of $\mathrm{MHC}$ molecules. CD8 binds to class I MHC molecules (26). This helps to explain why CD8 $\mathrm{T}$ cells tend to be involved in the response to endogenously synthesized antigens that are class $I$ MHC restricted. Most of these CD8 T cells have cytolytic function, and this function contributes to the elimination of virally infected cells. In contrast, CD4 binds to class II MHC molecules (27). This is consistent with the strong bias of CD4 $T$ cells, which usually function as helper cells, for antigenic peptides derived from exogenous sources or from the endocytic pathway which associate with class II MHC restricted antigens. These CD4 T cells respond to organisms which do not use host cell biosynthetic machinery.

On a distinct subset of $\mathrm{T}$ cells which generally do not express CD4 or CD8, $0.5-10 \%$ of peripheral T cells, another heterodimer termed the Ti $\gamma \delta$ is associated with the CD3 complex (28). Like the $\alpha$ and $\beta$ chains, the $\gamma$ and $\delta$ chains are also derived from immunoglobulinlike genes (reviewed in reference 28). However, unlike the cells that express $\mathrm{Ti} \alpha \beta$, the antigen reactivity of the cells bearing these receptors has been a matter of considerable controversy.

Cells expressing $\mathrm{Ti} \gamma \delta$ are the first antigen receptor-bearing cells to appear during thymic ontogeny $(29,30)$ but these receptors have very limited structural diversity and represent the precursors of $T$ cells that populate the murine epidermis (31, $32)$. Later during ontogeny, the $\mathrm{Ti} \gamma \delta$ chains on developing thymocytes exhibit greater diversity (33). In some species (chicken and mouse), it has been shown that $\mathrm{T}$ cells expressing the $\operatorname{Ti} \gamma \delta$ referentially localize within epithelial layers of tissues $(34,35)$. These cells may have a unique role in certain immune responses to antigens that could be presented by epithelial cells. Alternatively, these cells may represent an important surveillance mechanism, recognizing altered epithelial tissue that may be injured by environmental exposure. The limited diversity in the $\mathrm{Ti} \gamma \delta$ in the murine dentritic epidermal $\mathrm{T}$ cells has suggested that these receptors react with a well conserved 
antigen, i.e., heat shock proteins expressed by such damaged tissues (31). Reactivity to heat shock proteins by $\mathrm{T}$ cells expressing $\mathrm{Ti} \gamma \delta$ recently has been reported $(36,37)$. Increases in Ti $\gamma / \delta$-bearing cells have also been noted in granulomatous lesions of leprosy and cutaneous leishmaniasis (38). Moreover, mycobacterial antigen reactivity of $\gamma / \delta$ Ti-bearing cells isolated from rheumatoid synovial fluid or from sites of mycobacterial inoculation has been described $(39,40)$. However, the precise role of $\mathrm{T}$ cells expressing $\mathrm{Ti} \gamma \delta$ in host immunity awaits the development of better in vitro systems and the demonstration of their polyclonal responses to well defined antigens. The role of MHC molecules or class I MHC-related CD1 gene products in such antigen responses remains to be determined.

Both Ti $\alpha \beta$ and $\gamma \delta$ are associated with the CD3 complex. CD3 is comprised of the noncovalently associated homologous $\delta, \epsilon$, and $\gamma$ chains and associated disulfide-linked homo- or heterodimers of $\zeta-\zeta$ or $\zeta-\eta$ chains $(11,41,42,43)$. The $\zeta$ chain has little homology to the CD3 chains but is homologous to the $\gamma$ chain of the IgE Fc receptor which is also expressed as a disulfide-linked dimer (44). The $\eta$ chain represents an alternatively spliced protein product of the $\zeta$ chain gene (45). It has been suggested that the $\zeta-\zeta$ or $\zeta-\eta$ dimers are distinct subunits of the TCR, separate from the CD3 complex, perhaps with distinct functions in signal transduction (see below) (43, 46). Recently, the $\zeta-\zeta$ chain homodimer has also been shown to be expressed on natural killer cells in the absence of the TCR or other CD3 components (47). On these cells, the $\zeta$ chain is associated with CD16 (an Fc receptor) $(48,49)$ or as yet unidentified proteins (47).

It is widely assumed that CD3 plays a role in signal transduction. This notion has been supported by the observation that anti-CD3 mAbs mimic the function of antigen in activating $\mathrm{T}$ cells and from studies with somatic cell mutants with defective TCR-mediated signal transduction function $(50,51)$. Moreover, the structural complexity of the cytoplasmic domains of the CD3 chains $(40-115$ amino acids) $(11,43)$ compared to the scant information contained in the cytoplasmic tails of the Ti chains (5-12 amino acids) is consistent with this notion. CD3 is presumed to receive a signal from the ligandoccupied $\mathrm{Ti}$ and transmit this state of receptor occupancy by activating intracellular signal transduction mechanisms. The role of conformational changes, cross-linking, or aggregation in the activation of CD3 is not known.

\section{Genes encoding the Ti chains and their functions}

The genes encoding the Ti $\alpha, \beta, \gamma$, and $\delta$ chains are organized in a manner similar to immunoglobulin (Ig) genes (reviewed in reference 52 and Fig. $2 A$ ). During thymic ontogeny, these genes undergo recombination which involves the joining of individual variable $(\mathrm{V})$, diversity $(\mathrm{D})$, and joining $(\mathrm{J})$ region gene segments (Fig. $2 \mathrm{~B}$ ). As a result, a large repertoire of distinct TCR are generated and distributed in a clonal fashion. Rearrangement of these gene segments proceeds in an ordered and regulated process.

The mechanism of TCR gene segment recombination is similar to the one for Ig genes in pre-B cells (53). During recombination, the joining of $\mathrm{V} / \mathrm{D}(\beta$ and $\delta), \mathrm{V} / \mathrm{J}(\alpha$ and $\gamma)$, $\mathrm{D} / \mathrm{D}(\delta)$, or $\mathrm{D} / \mathrm{J}(\beta$ and $\delta$ ) region segments results in the looping out and deletion of the intervening DNA. The deleted products have been recovered from mouse thymus as circular DNA segments (54). In the severe combined immunodeficiency (SCID) mouse model the recombination process is defective
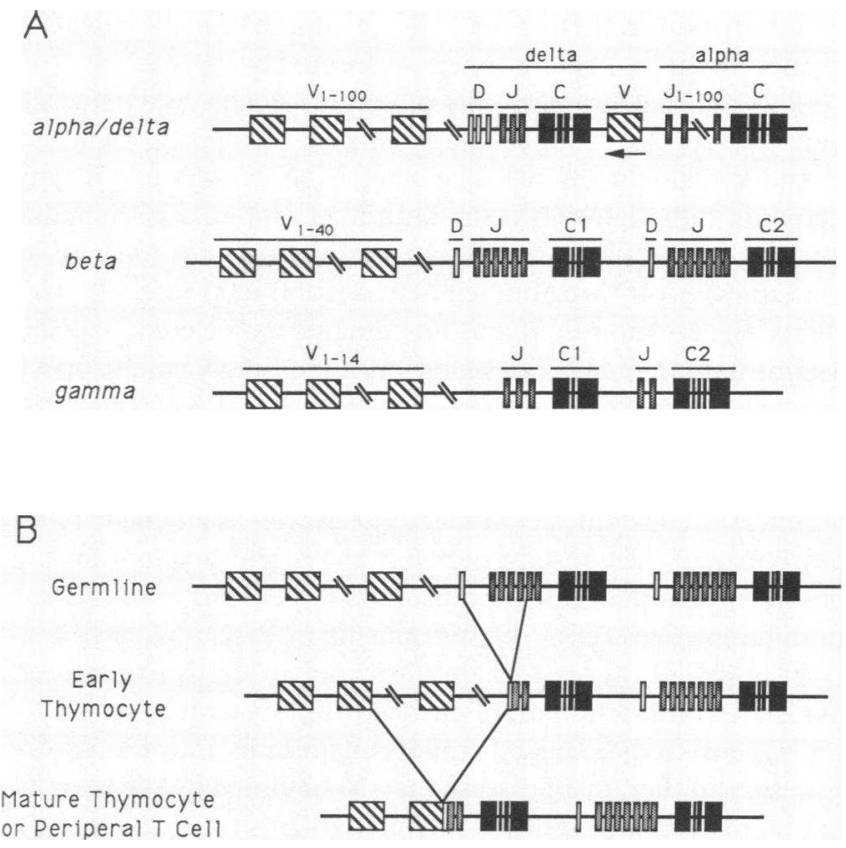

Figure 2. (A) Organization of the T cell receptor genes. (B) Example of the ordered stochastic rearrangement of the $\beta$ chain of the T cell receptor during $\mathrm{T}$ cell ontogeny.

and results in the imprecise joining of the gene segments (55). The defect in this mouse results in profound $T$ and $B$ cell defects. Whether some cases of SCID in man result from defects in the process of recombination awaits further investigation. The recombinase is thought to play a role in the numerous chromosomal translocations and inversions that involve the TCR genes in T cell tumors (52).

Each of the human TCR genes has a different organization with varying degrees of potential diversity generated by recombination of the available V, D, and $\mathrm{J}$ region segments (Fig. 2). Because the TCR is a two-chain structure, the various combinations of partner chains is quite large. However, nonrandom pairing of the protein products of at least the $\gamma$ and $\delta$ chains has been well documented $(31,56,57)$. This nonrandom pairing does not necessarily reflect an incompatibility of the $V$ regions in assembly of the $\gamma$ and $\delta$ chain proteins, but may result from thymic or peripheral selection.

The potential diversity of the TCR would appear much smaller than for Ig because the Ig heavy chain locus contains a much larger number of $\mathrm{V}$ region segments (in excess of 1,000). However, the potential repertoire of TCRs has been estimated to be much larger (reviewed in references 10 and 52). Diversity is greatly increased by flexibility at the $3^{\prime}$ junction of $\mathrm{V}$ and $\mathrm{D}$ segment junctions when recombined to $\mathrm{D}$ or $\mathrm{J}$ segments. In addition, variable numbers of additional nucleotides frequently found at the junctions of $V / D, V / J, D / D$, and $D / J$ segments greatly increase diversity of the TCR. These nucleotides, termed $\mathrm{N}$ regions, are added through the action of terminal deoxynucleotidyl transferase. Finally, the ability of the $\delta$ locus to use a variable number of $D$ segments also greatly amplifies the potential for diversity because each segment used has flexibility at the margin of the junction and variable numbers of $\mathrm{N}$-region nucleotides are added at each joint. These various mechanisms contribute to the generation of a poten- 
tially enormous repertoire of TCRs, estimated at $10^{17}$ and $10^{20}$ distinct $\alpha \beta$ and $\gamma \delta$ heterodimers, respectively $(10,52)$.

The unusual organization of the $\alpha / \delta$ locus bears special mention. The $\delta \mathrm{C}, \mathrm{J}$, and D segments are located between the $\mathrm{J}_{\alpha}$ - and $\mathrm{V}$-region segments. The $\alpha$ and $\delta$ loci can share $\mathrm{V}$-region segments, although only a small number of $\mathrm{V}$ regions actually appear to be utilized in the recombined $\delta$ genes (28). As a consequence of $\mathrm{V}$-region segment recombination to $\mathrm{J}_{\alpha}$ segments, the $\delta$ region $\mathrm{C}, \mathrm{J}$, and D segments are deleted. Specific regions flanking the $\delta$ locus have been identified which appear to play a role in $\delta$ gene deletion (58). In $\alpha / \beta$ TCR-bearing cells, both alleles of the $\delta$ locus are usually deleted.

Polymorphisms in the TCR loci have been described. Use of different constant region segments as well as an allelic polymorphism of the constant region of the $\gamma$ gene account for the observed disulfide- and nondisulfide-linked protein products of different sizes (28). Polymorphisms in $\mathrm{V}$ regions have also been observed. At least one of these polymorphisms has been associated with a human disease, multiple sclerosis (59).

Recent studies suggest important insights into the pathogenesis and therapy of disease may be obtained by the identification of particular TCR V region segments that are preferentially used in responses to defined antigens and in autoimmunity. Progress in identifying TCR V region segments that are preferentially expressed in complex mixtures of responding $T$ cells has come from the isolation of some TCR V region-specific monoclonal antibodies and the application of quantitative polymerase chain reaction technology. An excellent example of an oligoclonal response of pathogenic $T$ cells is the rodent model of experimental allergic encephalomyelitis (EAE) (60). These $T$ cells respond to peptides derived from myelin basic protein and express a restricted set of TCR $\mathrm{V}_{\alpha}$ and $V_{\beta}$ gene segments. Development of disease has been prevented in mice by using peptide analogues of the pathogenic peptide (61) or by vaccination with synthetic peptides derived from the $V_{\beta}$ sequence of the TCR expressed by the pathogenic $T$ cells $(62)$. Established active EAE in mice has been treated successfully with monoclonal antibody reactive with this $\mathrm{V}_{\beta}$ (63). Inspired by these studies in rodents, recent examination of patients with multiple sclerosis has suggested the involvement of oligoclonal $\mathrm{T}$ cell populations (64). Toxic shock syndrome may also result from the polyclonal activation of $\mathrm{T}$ cells which express particular $\mathrm{V} \beta$ region-derived products reactive with staphylococcal enterotoxins (65). These observations suggest therapeutic approaches towards preventing or treating human diseases involving oligoclonal T cell responses.

Somatic mutation of TCR genes does not appear to occur. This is in marked contrast to Ig genes where somatic mutation plays a major role in generating antibodies with higher affinities for antigen. Somatically mutated residues in Ig are found throughout the variable region. In contrast, the overwhelming degree of variability of the TCR is contained in the sequences of the VDJ junction, comparable to the CDR3 domain of immunoglobulin which is involved in formation of the pocket of the antibody binding site. These observations led to a model for antigen recognition by the TCR, which emphasizes why somatic mutation of TCR genes would not be desirable and that the variability in the TCR should be concentrated in the VDJ junction (10). According to this model, the TCR $\alpha$ and $\beta$ chains assume a conformation similar to that Ig. The $\mathrm{V}$ regions make contact with MHC molecule $\alpha$ helices, whereas the VDJ junction interacts with the associated peptide. Somatic mutation would impair MHC recognition, thus explaining the absence of somatic mutation of the TCR. This model is consistent with the limited number of TCR $\mathrm{V}$ regions that have evolved for the requisite $\mathrm{MHC}$ recognition and places a greater importance upon VDJ junctional diversity for peptide antigen recognition.

\section{Role of the $T$ cell antigen receptor in signal transduction}

The initiation of an immune response not only requires recognition of antigen by the TCR, but this recognition event must be translated into a transmembrane signal. This signal, in turn, leads to a cascade of intracellular events which influence cellular responses such as the transcriptional activation of lymphokine and lymphokine receptor genes, cell proliferation, or activation of the cytolytic effector mechanism. Although transmembrane signalling by the TCR may not be the sole signal transduction event required for $T$ cell activation, it certainly must play a primary role in regulating antigen-specific activation of T cells. Defective signal transduction by the TCR has been associated with a congenital immunodeficiency syndrome (66).

Two early signal transduction pathways are activated by stimulation of the TCR: the inositol phospholipid second messenger pathway and a tyrosine kinase pathway. Stimulation of $\mathrm{T}$ cells by antigen or anti-TCR mAbs induces rapid, large, and sustained increases in cytoplasmic free calcium $\left(\left[\mathrm{Ca}^{2+}{ }_{\mathrm{i}}\right)\right.$ as well as the activation of the calcium- and phospholipid-dependent serine and threonine kinase, protein kinase $C$ (PKC). Many studies suggest that these biochemical changes are physiologically important events initiated as a result of TCR stimulation (reviewed in reference 67).

The rise in $\left[\mathrm{Ca}^{2+}\right]_{i}$ and the activation of PKC have been observed in a wide variety of cells in response to stimulation of many distinct receptors which regulate the inositol phospholipid second messenger pathway (68). This involves receptormediated activation of a family of intracellular enzymes, termed phospholipase C (PLC) (69). The isozyme of PLC that is activated by TCR stimulation is not known. All of these enzymes cleave phosphatidylinositol 4,5-bisphosphate to yield two potent intracellular second messengers: inositol 1,4,5-trisphosphate $\left(\mathrm{IP}_{3}\right)$ and diacylglycerol (DG). These two potent second messengers are responsible for the mobilization of $\left[\mathrm{Ca}^{2+}\right]_{\mathrm{i}}$ and the activation of PKC, respectively.

The initial rise in $\left[\mathrm{Ca}^{2+}\right]_{i}$ is thought to result from the action of $\mathrm{IP}_{3}$ on a specific receptor within the endoplasmic reticulum which causes the release of calcium from sequestered stores (70). The sustained increase in $\left[\mathrm{Ca}^{2+}\right]_{i}$ depends upon a transmembrane flux of calcium (71) and may involve the response of an ill-defined calcium channel to inositol phosphates (72). However, it is possible that a passive transmembrane flux is only required to replenish inositol-sensitive intracellular stores of calcium.

While the precise mechanism by which the rise in $\left[\mathrm{Ca}^{2+}\right]_{i}$ leads to subsequent cellular responses is not known, it is likely that calcium-activated kinases play an important role. A sustained rise in the $\left[\mathrm{Ca}^{2+}\right]_{\mathrm{i}}$ appears to be necessary for several later cellular responses $(73,74)$. The best characterized of these cellular responses is the transcriptional activation of the IL-2 gene. Sustained second messenger generation may be required because the activation of the IL-2 gene is not a primary gene 
activation event. It depends upon the prior transcriptional activation of other immediate early activation genes (75). Indirect evidence would suggest that an important action of cyclosporin A, a potent immunosuppressive agent used commonly in modern transplantation, is to inhibit events which result from this increase in $\left[\mathrm{Ca}^{2+}\right]_{i}$, but before the transcriptional activation of the IL-2 gene $(75,76)$.

The other second messenger derived from the inositol phospholipid pathway is 1,2-diacylglycerol. Both diacylglycerol and phorbol esters activate PKC (77). Several different forms of PKC have been identified but the importance of the various isozymes is not known. These isozymes can be differentially expressed in $\mathrm{T}$ cells. Several $\mathrm{T}$ cell responses are not dependent on PKC $\beta$ (78). How PKC contributes to later cellular responses once activated is not clear. It is likely that a cascade of intracellular substrates may be involved in the response, including PKC-activated transcriptional factors (75). In addition, two PKC substrates are components of the TCR complex, the CD3 $\gamma$ and $\delta$ chains (79). Phosphorylation of these chains may be involved in regulating TCR function.

How the TCR activates PLC is not clear. Evidence from a variety of systems has suggested that guanine nucleotide binding $(G)$ proteins may serve to couple some receptors, particularly those with seven transmembrane domains, to PLC (80). The TCR contains seven transmembrane domains, albeit involving seven polypeptides comprising the receptor complex. Indirect evidence suggests that the $T$ cell antigen receptor is coupled to PLC via a G protein. However, alternative mechanisms involving the tyrosine kinase pathway in the regulation of PLC activation have recently gained support (see below). Indeed, relatively little progress has been made in identifying proteins that interact with the receptor upon ligand binding. However, recently, two integral membrane glycoproteins of 34 and $38 \mathrm{kD}$ have been identified which interact with the receptor upon ligand binding $(81)$. The function of these proteins is not known, but they may play a role in signal transduction because they do not interact with the TCR in somatic cell mutants that are defective in TCR-mediated activation of PLC.

The TCR also activates a tyrosine kinase activity that is not intrinsic to the TCR $(82,83)$. Stimulation of the TCR with antigen or with $\mathrm{mAbs}$ results in the phosphorylation on tyrosine residues of several proteins including the TCR $\zeta$ chain. Candidates for the kinase include lck and fyn, members of the src family of tyrosine kinases $(84,85)$. It has been shown that lck physically interacts with CD4 and CD8 (86). Cross-linking of CD4 results in increased lck activity and the phosphorylation of the TCR $\zeta$ chain (87). Very recent studies suggest an interaction between the TCR and fyn (88). How the TCR is coupled to the tyrosine kinase pathway is not known, but it is independent of the coupling of the TCR to PLC because hybridoma variants which are defective in TCR-induced PLC activation still activate the tyrosine kinase pathway (83).

Insight into the function of the tyrosine kinase pathway may come from studies of the CD45 (T200) family of proteins. These proteins, which are expressed on all leukocytes including $\mathrm{T}$ cells, have duplicated tyrosine phosphatase domains in their cytoplasmic domains (89). The regulation of a tyrosine kinase pathway could be intimately linked to the regulation of this tyrosine phosphatase. In support of this notion, a T cell clone that fails to express CD45 does not produce IL-2 or proliferate in response to antigen or anti-TCR mAb (90). Moreover, recent studies with a CD45 negative cell line suggest that the function of CD45 is essential for the activation of PLC by the TCR (91). Increased tyrosine phosphorylation of lck has been observed in some CD45 negative mutants (92). These studies suggest that CD45 may regulate the activity of $T$ cell tyrosine kinases and together they may have a complex relationship with the PLC that is activated by the TCR.

Whereas the relationship of the tyrosine kinase pathway and the inositol phospholipid pathway has not been established, the studies performed with CD45 negative mutants suggest that the tyrosine kinase may regulate the activation of PLC. This is supported by kinetic studies that suggest that the tyrosine kinase is activated before PLC (93). Direct phosphorylation of PLC and its association with stimulated epidermal growth factor and the platelet-derived growth factor receptors has been observed (94). Although the enzymatic activity of PLC was not shown to be altered by such phosphorylation, such studies suggest that this event may be important in receptor-mediated activation of the inositol phospholipid pathway. Thus, in $T$ cells, activation of a tyrosine kinase may represent the primary event which then serves to activate or regulate PLC activity, possibly by phosphorylation.

The relative importance of the tyrosine kinase and inositol phospholipid pathways in later cellular responses associated with $\mathrm{T}$ cell activation is not known. The requirement and involvement of the inositol phospholipid pathway in the activation of $T$ cells leading to IL-2 production was recently challenged by the isolation of a murine $\mathrm{T}$ cell hybridoma variant which produced normal levels of IL-2 upon TCR stimulation but failed to manifest detectable inositol phospholipid second messenger production (95). The explanation for the defect in this cell has been related to recent studies which indicate that a distinct form of the TCR, containing $\zeta-\eta$ dimers, is coupled to the inositol phospholipid pathway (46).

From the studies reported to date it would appear that the activation of the inositol phospholipid pathway can lead to $T$ cell activation responses. This has been further supported by more recent experiments in which a heterologous receptor that activates the inositol phospholipid pathway, the human muscarinic receptor subtype 1 , when expressed in $T$ cells can induce $T$ cell activation responses (Desai, D., and A. Weiss, unpublished data). Nevertheless, in order to understand the relative contributions of the two partially characterized signal transduction pathways and any other signal transduction events regulated by the TCR as well as by other cell surface molecules on the $\mathrm{T}$ cell, more progress in understanding how signal transduction events initiated at the plasma membrane regulate subsequent intracellular responses is required.

\section{Conclusion}

The $T$ cell antigen receptor is an extraordinarily complex cell surface receptor. Its importance in regulating $T$ cell recognition and activation makes it a critical component in all host immune responses for the clinician. Moreover, the study of the $T$ cell receptor has proved to be an important model not only for the immunologist, but also for the molecular geneticist to study TCR gene regulation and recombination as well as lymphokine gene regulation, for the developmental biologist to study thymic ontogeny, for the cell biologist to study the assembly of complex multichain plasma membrane proteins, 
and for the physiologist to study signal transduction. Thus, the study of the TCR is likely to yield important insights into basic biological processes and human disease.

\section{Acknowledgments}

The author would like to thank Dr. Gary Koretzky for his critical reading of the manuscript. This work was supported in part by $\mathrm{Na}$ tional Institutes of Health grant GM39553.

\section{References}

1. Unanue, E. R. 1984. Antigen-presenting function of the macrophage. Annu. Rev. Immunol. 2:395-428.

2. Townsend, A., and H. Bodmer. 1989. Antigen recognition by class I-restricted T lymphocytes. Annu. Rev. Immunol. 7:601-624.

3. Heath, W. R., M. E. Hurd, F. R. Carbone, and L. A. Sherman. 1989. Peptide-dependent recognition of H-2Kb by alloreactive cytotoxic T lymphocytes. Nature (Lond.). 341:749-752.

4. Germain, R. N. 1988. Antigen processing and CD4+ T cell depletion in AIDS. Cell. 54:441-444.

5. Chen, B. P., and P. Parham. 1989. Direct binding of influenza peptides to class I HLA molecules. Nature (Lond.). 337:743-745.

6. Babbitt, B. P., P. M. Allen, G. Matsueda, E. Haber, and E. R. Unanue. 1985. Binding of immunogenic peptides to Ia histocompatibility molecules. Nature (Lond.). 317:359-361.

7. Townsend, A., C. Ohlen, J. Bastin, H.-G. Ljunggren, L. Foster, and K. Karre. 1989. Association of class I major histocompatibility heavy and light chains induced by viral peptides. Nature (Lond.). 340:443-448.

8. Buus, S., A. Sette, S. M. Colon, C. Miles, and H. M. Grey. 1987. The relation between major histocompatibility complex (MHC) restriction and the capacity of Ia to bind immunogenic peptides. Science (Wash. DC. 235:1353-1358.

9. Bjorkman, P. J., M. A. Saper, B. Samraoui, W. S. Bennett, J. L. Strominger, and D. C. Wiley. 1987. The foreign antigen binding site and $\mathrm{T}$ cell recognition regions of class $\mathrm{I}$ histocompatibility antigens. Nature (Lond.). 329:512-518.

10. Davis, M. M., and P. J. Bjorkman. 1988. T-Cell antigen receptor genes and T-cell recognition. Nature (Lond.). 334:395-402.

11. Clevers, H., B. Alarcon, T. Willeman, and C. Terhorst. 1988. The T cell receptor/CD3 complex: a dynamic protein ensemble. Annu. Rev. Immunol. 6:629-662.

12. Brenner, M. B., I. S. Trowbridge, and J. L. Strominger. 1985. Crosslinking of human $T$ cell receptor proteins: association between the $T$ cell idiotype beta subunit and the T3 glycoprotein heavy subunit. Cell. 40:183-190.

13. Ohashi, P., T. Mak, P. Van den Elsen, Y. Yanagi, Y. Yasunobu, A. Calman, C. Terhorst, J. Stobo, and A. Weiss. 1985. Reconstitution of an active surface T3/T-cell antigen receptor by DNA transfer. $\mathrm{Na}$ ture (Lond.). 316:606-609.

14. Weissman, A. M., S. J. Frank, D. G. Orloff, M. Mercep, J. D. Ashwell, and R. D. Klausner. 1989. Role of the zeta chain in the expression of the $\mathrm{T}$ cell antigen receptor: genetic reconstitution studies. EMBO (Eur. Mol. Biol. Organ.) J. 8:3651-3656.

15. Alargon, B., J. R. Regueiro, A. Arnaiz-Villena, and C. Terhorst. 1988. Familial defect in the surface expression of the T-cell receptorCD3 complex. N. Engl. J. Med. 319:1203-1208.

16. Morley, B. J., K. N. Chin, M. E. Newton, and A. Weiss. 1988. The lysine residue in the membrane-spanning domain of the $\beta$ chain is necessary for cell surface expression of the $\mathrm{T}$ cell antigen receptor. $J$. Exp. Med. 168:1971-1978.

17. Bonifacino, J. S., C. K. Suzuki, and R. D. Klausner. 1990. A peptide sequence confers retention and rapid degradation in the endoplasmic reticulum. Science (Wash. DC). 247:79-82.

18. Dembic, Z., W. Haas, S. Weiss, J. McCubrey, H. Kiefer, H. von
Boehmer, and M. Steinmetz. 1986. Transfer of specificity by murine $\alpha$ and $\beta$ T-cell receptor genes. Nature (Wash. DC). 320:232-238.

19. Saito, T., A. Weiss, J. Miller, M. A. Norcross, and R. N. Germain. 1987. Specific antigen-Ia activation of transfected human $T$ cells expressing murine $\mathrm{Ti} \alpha \beta$-human $\mathrm{T} 3$ receptor complexes. Nature (Lond.). 325:125-130.

20. Teh, H. S., P. Kisielow, B. Scott, H. Kishi, Y. Uematsu, H. Bluthmann, and $H$. von Boehmer. 1988. Thymic major histocompatibility complex antigens and the $\alpha \beta$ T-cell receptor determine the CD4/CD8 phenotype of T cells. Nature (Lond.). 335:229-233.

21. Kappler, J. W., N. Roehm, and P. Marrack. 1987. T Cell tolerance by clonal elimination in the thymus. Cell. 49:273-280.

22. Kieselow, P., H. Bluthmann, U. D. Staerz, M. Steinmetz, and H. von Boehmer. 1988. Tolerance in T-cell-receptor transgenic mice involves deletion of nonmature CD4+8+ thymocytes. Nature (Lond.). 333:742-746.

23. Jenkins, M. K., R. H. Schwartz, and D. M. Pardoll. 1988. Effects of cyclosporine A on T cell development and clonal deletion. Science (Wash. DC). 241:1655-1658.

24. Sakaguchi, S., and N. Sakaguchi. 1988. Thymus and autoimmunity: transplantation of thymus from cyclosporin A-treated mice causes organ-specific autoimmune disease in athymic nude mice. $J$. Exp. Med. 167:1479-1485.

25. Hood, A. F., G. B. Vogelsang, L. P. Black, E. R. Farmer, and G. W. Santos. 1987. Acute graft-vs.-host disease. Arch. Dermatol. 123:745-750.

26. Norment, A. M., R. D. Salter, P. Parham, V. H. Engelhard, and D. R. Littman. 1988. Cell-cell adhesion mediated by CD8 and MHC class I molecules. Nature (Lond.). 336:79-81.

27. Doyle, C., and J. L. Strominger. 1988. Interaction between CD4 and class II MHC molecules mediates cell adhesion. Nature (Lond.). 330:256-258.

28. Brenner, M. B., J. L. Strominger, and M. S. Krangel. 1988. The $\gamma \delta \mathrm{T}$ cell receptor. Adv. Immunol. 43:133-191.

29. Havran, W. L., and J. P. Allison. 1988. Developmentally ordered appearance of thymocytes expressing different T-cell antigen receptors. Nature (Lond.). 335:443-445.

30. Sowder, J. T., C.-L. H. Chen, L. L. Ager, M. M. Chan, and M. D. Cooper. 1988. A large subpopulation of avian T cells express a homologue of the mammalian T $\gamma / \delta$ receptor. J. Exp. Med. 167:315322.

31. Asarnow, D. M., W. A. Kuziel, M. Bonyhadi, R. E. Tigelaar, P. W. Tucker, and J. P. Allison. 1988. Limited diversity of $\gamma \delta$ antigen receptor genes of Thy-1+ dendritic epidermal cells. Cell. 55:837-847.

32. Havran, W. L., and J. P. Allison. 1990. Origin of Thy-1+ dendritic epidermal cells of adult mice from fetal thymic precursors. Nature (Lond.). 344:68-70.

33. Elliot, J. F., E. P. Rock. P. A. Pattern, M. M. Davis, and Y. Chien. 1988. The adult T cell receptor $\delta$ chain is diverse and distinct from that of fetal thymocytes. Nature (Lond.). 331:627-631.

34. Goodman, T., and L. Lefrancois. 1988. Expression of the $\gamma-\delta$ T-cell receptor on intestinal CD8+ intraepithelial lymphocytes. Nature (Lond.). 333:855-857.

35. Bucy, R. P., C.-L. H. Chen, J. Cihak, U. Losch, and M. D. Cooper. 1988. Avian T cells expressing $\gamma \delta$ receptors localize in the splenic sinusoids and the intestinal epithelium. J. Immunol. 141:2200-2205.

36. Haregewoin, A., G. Soman, R. C. Hom, and R. W. Finberg. 1989. Human $\gamma \delta+T$ cells respond to mycobacterial heart-shock protein. Nature (Lond.). 340:309-312.

37. O'Brien, R. L., M. P. Happ, A. Dallas, E. Palmer, R. Kubo, and W. K. Born. 1989. Stimulation of a major subset of lymphocytes expressing $T$ cell receptor $\gamma \delta$ by an antigen derived from mycobacterium tuberculosis. Cell. 57:667-674.

38. Modlin, R. L., C. Pirmez, F. M. Hofman, V. Torigian, K. Uyemura, T. H. Rea, B. R. Bloom, and M. B. Brenner. 1989. Lymphocytes bearing antigen-specific $\gamma \delta$ T-cell receptors accumulate in 
human infectious disease lesions. Nature (Lond.). 339:544-548.

39. Holoshitz, J., F. Koning, J. E. Coligan, J. De Bruyn, and S. Strober. 1989. Isolation of CD4- CD8- mycobacteria-reactive T lymphocyte clones from rheumatoid arthritis synovial fluid. Nature (Lond.). 339:226-229.

40. Janis, E. M., S. H. E. Kaufmann, R. H. Schwartz, and D. M. Pardoll. 1989. Activation of $\gamma \delta \mathrm{T}$ cells in the primary immune response to Mycobacterium tuberculosis. Science (Wash. DC). 244:713716.

41. Samelson, L. E., J. B. Harford, and R. D. Klausner. 1985. Identification of the components of the murine $\mathrm{T}$ cell antigen receptor complex. Cell. 43:223-231.

42. Baniyash, M., P. Garcia-Morales, J. S. Bonifacino, L. E. Samelson, and R. D. Klausner. 1988. Disulfide linkage of the $\zeta$ and $\eta$ chains of the T cell receptor. J. Biol. Chem. 263:9874-9878.

43. Weissman, A. M., D. Hou, D. G. Orloff, W. S. Modi, H. Seuanez, S. J. O'Brien, and R. D. Klausner. 1988. Molecular cloning and chromosomal localization of the human T-cell receptor $\zeta$ chain: distinction from the molecular CD3 complex. Proc. Natl. Acad. Sci. USA. 85:9709-9713.

44. Blank, U., C. Ra, L. Miller, K. White, H. Metzger, and J.-P. Kinet. 1989. Complete structure and expression in transfected cells of high affinity IgE receptor. Nature (Lond.). 337:187-189.

45. Jin, Y.-J., L. K. Clayton, F. D. Howard, S. Koyasu, M. Sieh, R. Steinbrich, G. E. Tarr, and E. L. Reinherz. 1990. Molecular cloning of the $\mathrm{CD} 3 \eta$ subunit identifies a $\mathrm{CD} 3 \zeta$-related product in thymus-derived cells. Proc. Natl. Acad. Sci. USA. 87:3319-3323.

46. Mercep, M., J. S. Bonifacino, P. Garcia-Morales, L. E. Samelson, R. D. Klausner, and J. D. Ashwell. 1988. T cell CD3- $\zeta \eta$ heterodimer expression and coupling to phosphoinositide hydrolysis. Science (Wash. DC). 242:571-574.

47. Anderson, P., M. Caligiuri, J. Ritz, and S. F. Schlossman. 1989. CD3-negative natural killer cells express $\zeta$ TCR as part of a novel molecular complex. Nature (Lond.). 341:159-162.

48. Lanier, L. L., G. Yu, and J. H. Phillips. 1989. Co-association of $\mathrm{CD} 3 \mathrm{z}$ with a receptor (CD16) for IgG Fc on human natural killer cells. Nature (Lond.). 342:803-805.

49. Anderson, P., M. Caligiuri, C. O'Brien, T. Manley, J. Ritz, and S. F. Schlossman. 1990. Fc $\gamma$ receptor type III (CD16) is included in the $\zeta$ NK receptor complex expressed by human natural killer cells. Proc. Natl. Acad. Sci. USA. 87:2274-2278.

50. Goldsmith, M. A., and A. Weiss. 1987. Isolation and characterization of a T-lymphocyte somatic mutant with altered signal transduction by the antigen receptor. Proc. Natl. Acad. Sci. USA. 84:68796883.

51. Sussman, J. J., J. S. Bonifacino, J. Lippincott-Schwartz, A. M. Weissman, T. Saito, R. D. Klausner, and J. D. Ashwell. 1988. Failure to synthesize the T cell CD3- $\zeta$ chain: structure and function of a partial T cell receptor complex. Cell. 52:85-95.

52. Boehm, T., and T. H. Rabbits. 1989. The human T cell receptor genes are targets for chromosomal abnormalities in $\mathrm{T}$ cell tumors. FASEB (Fed. Am. Soc. Exp. Biol.) J. 3:2344-2359.

53. Blackwell, T. K., and F. W. Alt. 1989. Molecular characterization of the lymphoid V(D)J recombination activity. J. Biol. Chem. 264:10327-10330.

54. Okazaki, K., and H. Sakano. 1988. Thymocyte circular DNA excised from T cell receptor alpha-delta gene complex. EMBO (Eur Mol. Biol. Organ.) J. 7:1669-1674.

55. Lieber, M. R., J. E. Hesse, S. Lewis, G. C. Bosma, N. Rosenberg, K. Mizuuchi, M. J. Bosma, and M. Gellert. 1988. The defect in the murine severe combined immune deficiency: joining of signal sequences but not coding segments in V(D)J recombination. Cell. 55:7-16.

56. Lanier, L. L., J. Ruitenberg, R. L. H. Bolhuis, J. H. Phillips, and R. Tseti. 1988. Structural and serological heterogeneity of $\gamma / \delta$ T cell antigen receptor expression in thymus and peripheral blood. Eur. $J$. Immunol. 18:1985-1992.
57. Raulet, D. H. 1989. The structure, function and molecular genetics of the gamma/delta T cell receptor. Annu. Rev. Immunol. 7:175-208

58. Hockett, R. D., J.-P. De Villartay, K. Pollock, D. G. Poplack, D. J. Cohen, and S. J. Korsmeyer. 1988. Human T-cell antigen receptor (TCR) $\delta$-chain locus and elements responsible for its deletion are within the TCR $\alpha$-chain locus. Proc. Natl. Acad. Sci. USA. 85:96949698.

59. Seboun, E., M. A. Robinson, T. H. Doolittle, T. A. Ciulla, T. J. Kindt, and S. L. Hauser. 1989. A susceptibility locus for multiple sclerosis is linked to the $\mathrm{T}$ cell receptor $\beta$ chain complex. Cell. 57:1095-1100.

60. Acha-Orbea, H., L. Steinman, and H. O. McDevitt. 1989. T cell receptors in murine autoimmune diseases. Annu. Rev. Immunol. 7:371-406.

61. Wraith, D. C., D. E. Smilek, D. J. Mitchell, L. Steinman, and H. O. McDevitt. 1989. Antigen recognition in autoimmune encephalomyelitis and the potential for peptide-mediated immunotherapy. Cell. 59:247-255.

62. Vandenbark, A. A., G. Hashim, and H. Offner. 1989. Immunization with a synthetic T-cell receptor $\mathrm{V}$-region peptide protects against experimental autoimmune encephalomyelitis. Nature (Lond.). 341:541-544.

63. Acha-Orbea, H., D. J. Mitchell, L. Timmermann, D. C. Wraith, G. S. Tausch, M. K. Waldor, S. S. Zamvil, H. O. McDevitt, and L. Steinman. 1988. Limited heterogeneity of T cell receptors from lymphocytes mediating autoimmune encephalomyelitis allows specific immune intervention. Cell. 54:263-273.

64. Oksenberg, J. R., S. Stuart, A. B. Begovich, R. B. Bell, H. A. Erlich, L. Steinman, and C. C. A. Bernard. 1990. Limited heterogeneity of rearranged T-cell receptor $\mathrm{V} \alpha$ transcripts in brains of multiple sclerosis patients. Nature (Lond.). 345:344-346.

65. Choi, Y., B. Kotzin, L. Herron, J. Callahan, P. Marrack, and J. Kappler. 1989. Interaction of staphylococcus aureus "superantigens" with human T cells. Proc. Natl. Acad. Sci. USA. 86:8941-8945.

66. Chatila, T., R. Wong, M. Young, R. Miller, C. Terhorst, and R. S. Geha. 1989. An immunodeficiency characterized by defective signal transduction in T lymphocytes. N. Engl. J. Med. 320:696-702.

67. Weiss, A., and J. B. Imboden. 1987. Cell surface molecules and early events involved in human T lymphocyte activation. $A d v . I m$ munol. 41:1-38.

68. Berridge, M. J. 1987. Inositol trisphosphate and diacylglycerol: two interacting second messengers. Annu. Rev. Biochem. 56:159-193.

69. Rhee, S. G., P.-G. Suh, S.-H. Ryu, and S. Y. Lee. 1989. Studies of inositol phospholipid-specific phospholipase C. Science (Wash. $D C)$. 244:546-550.

70. Ferris, C. D., R. L. Huganir, S. Supattapone, and S. H. Snyder. 1989. Purified inositol 1,4,5-trisphosphate receptor mediates calcium flux in reconstituted lipid vesicles. Nature (Lond.). 342:87-89.

71. Imboden, J. B., and J. D. Stobo. 1985. Transmembrane signalling by the $T$ cell antigen receptor: perturbation of the $T 3$-antigen receptor complex generates inositol phosphates and releases calcium ions from intracellular stores. J. Exp. Med. 161:446-456.

72. Kuno, M., and P. Gardner. 1987. Ion channels activated by inositol 1,4,5-trisphosphate in plasma membrane of human T-lymphocytes. Nature (Lond.). 326:301-304.

73. Weiss, A., R. Shields, M. Newton, B. Manger, and J. Imboden. 1987. Ligand-receptor interactions required for commitment to the activation of the interleukin 2 gene. J. Immunol. 138:2169-2176.

74. Goldsmith, M., and A. Weiss. 1988. Early signal transduction by the antigen receptor without commitment to $\mathrm{T}$ cell activation. Science (Wash. DC). 240:1029-1031.

75. Crabtree, G. 1989. Contingent genetic regulatory events in T lymphocyte activation. Science (Wash. DC). 243:355-361.

76. Manger, B., K. J. Hardy, A. Weiss, and J. D. Stobo. 1986. Differential effect of cyclosporin A on activation signaling in human $\mathrm{T}$ cell lines. J. Clin. Invest. 77:1501-1506. 
77. Nishizuka, Y. 1986. Studies and perspectives of protein kinase C. Science (Wash. DC). 233:305-312.

78. Koretzky, G. A., M. Wahi, M. E. Newton, and A. Weiss. 1989. Heterogeneity of protein kinase $C$ isoenzyme gene expression in human $T$ cell lines: protein kinase $C-\beta$ is not required for several $T$ cel functions. J. Immunol. 143:1692-1695.

79. Cantrell, D. A., A. A. Davies, and M. J. Crumpton. 1985. Activators of protein kinase $C$ down-regulate and phosphorylate the T3/T-cell antigen receptor complex of human T lymphocytes. Proc. Natl. Acad. Sci. USA. 82:8158-8162.

80. Cockcroft, A. 1987. Polyphosphoinositide phosphodiesterase: regulation by a novel guanine nucleotide binding protein, $\mathrm{G}_{\mathrm{p}}$. TIBS (Trends Biochem. Sci.). 12:75-78.

81. Fraser, J. D., M. A. Goldsmith, and A. Weiss. 1989. Ligand-induced association between the T-cell antigen receptor and two glycoproteins. Proc. Natl. Acad. Sci. USA. 86:7133-7137.

82. Samelson, L. E., M. D. Patel, A. M. Weissman, J. B. Harford, and R. D. Klausner. 1986. Antigen activation of murine T cells induces tyrosine phosphorylation of a polypeptide associated with the $T$ cell antigen receptor. Cell. 46:1083-1090.

83. Ashwell, J. D., and R. D. Klausner. 1990. Genetic and mutational analysis of the T cell antigen receptor. Annu. Rev. Immunol. 8:139-168

84. Marth, J. D., R. Peet, E. G. Krebs, and R. M. Perlmutter. 1985. A lymphocyte-specific protein-tyrosine kinase in the murine $T$ cell lymphoma LSTRA. Cell. 43:393-404.

85. Cooke, M. P., and R. M. Perlmutter. 1989. Expression of a novel form of the fyn proto-oncogene in hematopoietic cells. New Biologist. 1:66-74.

86. Veillette, A., M. A. Bookman, E. M. Horak, and J. B. Bolen. 1988. The CD4 and CD8 T cell surface antigens are associated with the internal membrane tyrosine-protein kinase p56 ${ }^{\text {lck }}$. Cell. 55:301-308.

87. Veillette, A., M. A. Bookman, E. M. Horak, L. E. Samelson, and J. B. Bolen. 1989. Signal transduction through the CD4 receptor involves the activation of the internal membrane tyrosine-protein kinase p56lck. Nature (Lond.). 338:257-259.

88. Samelson, L. E., A. F. Phillips, E. T. Luong, and R. D. Klausner. 1990. Association of the fyn protein-tyrosine kinase with the T-cell antigen receptor. Proc. Natl. Acad. Sci. USA. 87:4358-4362.

89. Tonks, N. K., H. Charbonneau, C. D. Diltz, E. H. Fischer, and K. A. Walsh. 1988. Demonstration that the leukocyte common antigen CD45 is a protein tyrosine phosphatase. Biochemistry. 27:86958701.

90. Pingel, J. T., and M. L. Thomas. 1989. Evidence that the leukocyte-common antigen is required for antigen-induced $\mathrm{T}$ lymphocyte proliferation. Cell. 58:1055-1065.

91. Koretzky, G. A., J. Picus, M. L. Thomas, and A. Weiss. 1990. The tyrosine phosphatase CD45 is essential for coupling of the $T$ cell antigen receptor to the phosphatidylinositol second messenger pathway. Nature (Lond.). 346:66-68.

92. Ostergaard, H. L., D. A. Shackelford, T. R. Hurley, P. Johnson, R. Hyman, B. M. Sefton, and I. S. Trowbridge. 1989. Expression of CD45 alters phosphorylation of the lck-encoded tyrosine protein kinase in murine lymphoma T-cell lines. Proc. Natl. Acad. Sci. USA. 86:8959-8963.

93. June, C. H., M. C. Fletcher, J. A. Ledbetter, and L. E. Samelson. 1990. Increases in tyrosine phosphorylation are detectable before phospholipase $\mathrm{C}$ activation after $\mathrm{T}$ cell receptor stimulation. J. Immunol. 144:1591-1599.

94. Wahl, M. I., S. Nishibe, P.-G. Suh, S. G. Rhee, and G. Carpenter. 1989. Epidermal growth factors stimulates tyrosine phosphorylation of phospholipase C-II independently of receptor internalization and extracellular calcium. Proc. Natl. Acad. Sci. USA. 86:1568-1572.

95. Sussman, J. J., M. Mercep, T. Saito, R. N. Germain, E. Bonvini, and J. D. Ashwell. 1988. Dissociation of phosphoinositide hydrolysis and $\mathrm{Ca}^{2+}$ fluxes from the biological responses of a T-cell hybridoma. Nature (Lond.). 334:625-628. 